Federal Reserve Bank of Minneapolis

Research Department Working Paper

FATHER OF FINANCIAL INTERMEDIARY-COALITIONS

John H. Boyd and Edward C. Prescott*

Working Paper 250

PACS File 3050

March 1984

NOT FOR DISTRIBUTION

WITHOUT AUTHORS' APPROVAL

*Authors are affiliated with Minneapolis Federal Reserve Bank and the University of Minnesota. We thank Jack Kareken for interesting us in this project and providing insightful comments. We also thank workshop participants at Carnegie-Mellon University, the University of Chicago, the University of Pennsylvania and the Minneapolis Federal Reserve Bank, in particular, Edward J. Green, Bruce Smith, Mike Stutzer and Oliver E. Williamson. We gratefully acknowledge financial support of the National Science Foundation.

The views expressed are those of the authors and not necessarily those of the Federal Reserve Bank of Minneapolis or the Federal Reserve System. The material contained is of a preliminary nature, is circulated to stimulate discussion, and is not to be quoted without permission of the authors. 
Federal Reserve Bank of Minneapolis

Research Department Staff Report 87

October 1984

FATHER OF FINANCIAL INTERMEDIARY-COALITIONS

John H. Boyd

Edward C. Prescott

Federal Reserve Bank of Minneapolis

and

University of Minnesota

The views expressed herein are those of the authors and not necessarily those of the Federal Reserve Bank of Minneapolis or the Federal Reserve System.

We thank Jack Kareken for interesting us in this project and providing insightful comments. We also thank workshop participants at CarnegieMellon University, the University of Chicago, the University of Pennsylvania, and the Federal Reserve Bank of Minneapolis--in particular, Edward J. Green, Bruce D. Smith, Michael J. Stutzer, and Oliver E. Williamson. We gratefully acknowledge financial support from the National Science Foundation. 
1. Introduction

A great deal has been written about financial intermediaries and there is general agreement that these firms are somehow important. They account for about 10 percent of measured GNP in developed economies, and likely play an important role in the transmission of monetary policy. In the Arrow-Debreu paradigm, however, the existence of financial intermediaries is a paradox. With price taking by all agents, no frictions and no private information, intermediaries need not exist since they can do nothing better or more than individual agents can do for themselves (Fama [1980]). As a result, serious analysis of intermediaries has been hindered by the lack of a convincing general equilibrium theory that gives rise to trading frictions.

In the last several years, a few authors have exploited recent advances in information economics, applying them to the study of financial intermediation. (For example, Townsend [1978, 1983], Diamond and Dybvig [1983] Smith [1983]). Our paper is in this spirit. We assume a simple economy in which information about real investment opportunities (called projects) is private. A form of financial intermediary is shown to endogenously emerge in this environment and to perform an important function not performed by securities markets; that is, it permits the efficient production and use of information about projects. In this economy, agents form coalitions that resemble financial intermediary firms, simply because it is in their own interest to do so. Moreover, these primitive intermediary-coalitions exhibit some important attributes like those observed in virtually all real-world intermediaries. It is definitional that they borrow from one subset of agents in the economy and lend to another. More specifically, however, our intermediarycoalitions exhibit the following characteristics.1/ 
i. They produce costly information on the attributes of wouldbe borrowers, which is then used to allocate loans.

ii. They issue their own securities which have different state contingent payoffs than claims issued by ultimate borrowers.

iii. They borrow from and lend to a large number of agents. To the extent that numbers measure diversification, they are highly diversified on both sides of their balance sheets.

All of these characteristics prove to be important in supporting an equilibrium allocation with intermediary-coalitions. It is particularly interesting that assets and liabilities must be diversified, even though we assume all agents are risk-neutral.

The analysis has some additional features that may be of interest, beyond those results pertaining to financial intermediation. Unlike many private information economies, the ones we study require trade between classes of agents to achieve Pareto optimal allocations. This is true in our economies even in the limiting case in which all information is public. Obviously, we structured such environments because we needed trade in a model used to investigate borrowing and lending decisions. However, this class of private information economy might also prove useful for studying other issues that require explicit consideration of the gains from trade.

In addition, we assumed a production technology that is costlessly and directly available to any agent or group of agents. This is in contrast to the standard general equilibrium approach of assuming a set of technologies which are called "firms," and some distribution of ownership of profits resulting from operations of these technologies. The equilibrium concept employed here is related to that of the core. There are, however, two important differences necessitated by private 
information considerations. First, we assume that coalitions have access to a contracting technology which can preclude subsequent recontracting. Second, we assume that agents cannot be excluded from coalitions based upon private information of their types. For our economies, core equilibrium allocations exist and are essentialiy unique. Like large pure exchange economics, the distributions of the gains from trade depend upon the relative numbers of different agent types.

Summary and Overview of What Follows

Briefly, the rest of the paper proceeds as follows. Section 2 specifies a two-period private information econonv. Section 3 investigates equilibrium allocations for this econory, assuming that no agent is endowed with private information, but any agent may pay to obtain it. Three cases are considered. It is first shown that when all agents are pathologically honest, an efficient allocation is one which provides the same ex ante consumption to everyone. This allocation is supported by a securities market, and there is no need for intermediation. This is just one of a number of arrangements, however, that would work equally well. Second, we show that if the assumption of pathological honesty is dropped, the securities market fails. It fails in the sense that, even though the production of investment information would increase aggregate consumption, no agent will produce it unilaterally. What is required is an arrangement that resembles a financial intermediary.

The third case considered is one such arrangement: a coalition of $n$ agents who specify rules for group investment, evaluation, and consumption outcomes. It is shown that if $\mathrm{n}$ is sufficiently large these rules are feasible. The arrangement supports the optimal allocation for the economy described previously, the one with pathological honesty, and must therefore be optimal in the presence of moral hazard. 
In Section 4, we introduce the possibility of adverse selection by assuming that each agent is endowed with private information. As before, all agents can also produce private information if they so choose. Then, we examine the same three cases considered in Section 3. First is the simplest case, pathological honesty on the part of all agents. Next, we characterize an equilibrium for this economy assuming that agents are willing to lie, but that legal restrictions prohibit the formation of intermediary-coalitions. This is done to sharply contrast a world with, and without, financial intermediaries. An equilibrium allocation is defined and supported with a securities market. In this equilibrium as in the previous one, without intermediaries there is no way to realize a return on private information and none is produced.

The third case is presented in Section 5, where we drop the legal restrictions on the formation of intermediary-coalitions. It is shown that under certain conditions these organizations will endogenously emerge, and information will be produced. (Later, in Section 6, a numerical example is provided showing that the set of economies for which these conditions hold is nonempty.) The equilibrium institutional arrangement is more complicated than the previous one, but as before intermediaries are coalitions which specify investment rules, evaluation, and compensations in an incentive compatible manner. Finally, it is shown that an arrangement with an industry of competing intermediary-coalitions supports an equilibrium allocation that is unique and Pareto optimal. Section 7 discusses possible extensions and concludes the paper. 


\section{The Economy}

There is a countable infinity of agents that live two periods. They are endowed with one unit of time in the initial period and an investment project of either a good type $i=g$ or $a$ bad type $i=b$. Using their endowment of time they can in the first period either produce one unit of the investment good or evaluate a project. Agents' preferences are ordered by expected consumption in the second and final period. Thus,

$$
E\{c\}
$$

orders the distribution of consumptions where $E\{\}$ is the expectation operator. Consumption is necessarily nonnegative, an assumption which plays an important role in the analysis.

The rate of return per unit of investment in a project is either $r=b$ or $r=g$ where $g>b$ for investments $x$ in the range $0 \leqslant x$ $\leqslant x$. Here $x$ is the maximum investment in a project, and it is assumed that $x$ is large relative to an individual's one unit endowment of the investment good. If a project is evaluated, $a$ signal $e=b$ or $e=g$ is observed, which is private to the evaluator. This signal provides information about the rate of return on the project, which may be better or worse than the information provided by project type. This concept will now be made precise.

Project, or agent, types $(i, e, r)$ are identical and independent draws with $\pi(i, e, r)$ denoting the probability of type (i,e,r) $\varepsilon$ $\{\mathrm{g}, \mathrm{b}\} \times\{\mathrm{g}, \mathrm{b}\} \times\{\mathrm{g}, \mathrm{b}\}$. There being a countable infinity of agents, throughout this analysis we consider the fractions of the various types which are just the $\pi(i, e, r)$ and write resource constraints in per capita 
terms. For a rigorous justification of this procedure see Green [forthcoming].

Agents in this economy know their own type $i=g$ or $b$ and, of course, the probabilities $\pi(i, e, r)$. They do not have the opportunity to enter into contracts prior to observing their i. Throughout, expectations are with respect to the probability distribution defined by the $\pi(i, e, r)$. If a project is evaluated, then the evaluator's private information about the project is e $\varepsilon\{g, b\}$. That he evaluated, however, is public knowledge. If a project is funded this is public knowledge, and the return $r$ on the project is publicly observed in the second period. Also, publicly observed in the second period are all agents' consumption outcomes.

It is further assumed that $i=g$ and/or $e=g$ signals that the return on the project will be high, or that $r=g$. That is,

$$
\pi\{r=g \mid i=g\} \geqslant \pi\{r=g \mid i=b\}
$$

and

$$
\pi\{r=g \mid e=g\}>\pi\{r=g \mid e=b\}
$$

Finally, all the $\pi(i, e, r)$ are strictly positive so signals are imperfect and it is impossible to deduce $i$ given the evaluation $e$ and the return $r$. Figure 1 below indicates the timing of various events and actions during the two periods.

\section{Figure 1}

Period 1

- All agents know whether their project is of type $i=g$ or $i=b$, prior to any contracting opportunities.

- Agents can enter into contracts. 
- Agents can evaluate.

- Investments are made.

$\underline{\text { Period } 2}$

- Projects returns are realized and observed by all.

- Consumption occurs and is observed by all.

Resource constraints are that per capita investment in projects plus the fraction of the projects evaluated is constrained by per capita endowment, and that per capita consumption is constrained by per capita production of the consumption good.

(2.1) Total investment per capita + total number of evaluations per capita $\leqslant$ total endowment per capita.

(2.2) Per capita consumption $\leqslant$ Per capita production of the consumption good.

Throughout this paper no intermediary has any monopoly power. In the economies described later, with competing intermediary-coalitions this is accomplished by having a countable infinity of agents and by intermediaries being "small" in the sense that the fraction of all agents which are any intermediary's customer is zero. At the same time, intermediaries are "large" in the sense that each has a countable infinity of borrowers and lenders. $\underline{\text { I }}$ As discussed later, each intermediary must deal with a large number of agents in order to insure that it can meet its contractual obligations almost surely. 
3. Equilibrium Allocations Without Adverse Selection

We first abstract from the adverse selection problem by assuming an agent's type $i$ is independent of both the evaluation $e$ and return $r$ of that agent's project. This being the case, the $i$ plays no role in the analysis and consequently is dropped in this section. For present purposes, the interesting cases are those in which there will be evaluation for the Pareto optimal allocation. Thus, in this section parameter values are restricted to those which satisfy

$$
\chi \pi(e=g)[E\{r \mid e=g\}-E\{r\}]>E\{r\} \text {. }
$$

$E\{r \mid e=g\}-E\{r\}$ is the increase in the expected rate of return when a good evaluation is obtained, and $\pi(e=g)$ is the probability that this will occur. $x$ is the maximum amount of investment possible in a project. Thus, the left side of (3.1) is the expected return to investing in one evaluation. The right side of (3.1) is the expected opportunity cost of investing in one evaluation.

\section{All Agents Are Honest}

First, suppose that people are pathologically honest and never lie. For this economy a social optimum, which provides the same ex ante welfare to all, is as follows. Fraction y of projects are evaluated, where y satisfies

$$
\text { (3.2) } \quad x \pi(e=g) y=1-y \text {. }
$$

Amount $x$ is invested in evaluated projects which prove to be promising; and all agents have consumption lotteries with

$$
\text { (3.3) } \quad E\{c\}=\chi E\{r \mid e=g\} \pi(e=g) y \text {. }
$$


Condition (3.2) requires that just enough projects are evaluated so that, if the good ones are funded at level $x$, all the endowment of the investment good remaining after the evaluation is invested. Condition (3.3) is that per capita consumption equals per capita output of the consumption good.

When all agents are pathologically honest this allocation can be supported by any of a number of arrangements, including a market for shares. Suppose, for example, that fraction $y$ of agents evaluate their projects and fraction 1 - y, called "investors," do not. Those who evaluate their projects, and are fortunate enough to have good projects, become "entrepreneurs" and issue shares. For one unit of the investment good, an investor receives a share which promises to pay a fraction s of the project's period two total output, with

(3.4) $\quad s=y \pi(e=g)$.

The number of shares issued is $x$ for this is the amount needed to fully fund the project. Each entrepreneur retains a claim on 1 - $x$ s percent of the firm's period two output. Those who evaluate their projects and are unfortunate in receiving a bad evaluation consume zero. Investors receive the expected consumption specified in (3.3). Entrepreneurs receive expected consumption in (3.3) divided by $\pi(e=g)$. Ex ante, those who evaluate projects also have expected consumption given in (3.3). But, some are fortunate (obtain $\mathrm{e}=\mathrm{g}$ and become entrepreneurs) and receive greater expected consumption after evaluation, while others are unfortunate (obtain $e=b$ ) and consume zero. 
Agents May be Dishonest--Intermediaries Emerge

This scheme will not work if it is known that agents may be dishonest. There is then an incentive for those with bad evaluations to claim otherwise and issue shares anyway. It is costless for them to do so. Thus, no agent who evaluates will ever announce a bad outcome, and for this reason markets for information will fail. Without some more complicated contractual arrangement, there is no way to realize the gains from investing in evaluation.

We next show that there is an arrangement, which overcomes this problem. First, we define an "intermediary-coalition." Then we show how an arrangement with competing intermediary-coalitions can support an optimal allocation for this economy.

Definition: An intermediary-coalition is a coalition of two or more agents who evaluate projects. It publicly announces an evaluation policy, an investment policy (which may be conditional on evaluation outcomes), compensation schedules for coalition members, and compensation schedules for other agents that contract with it.

In the particular economy we are now considering, suppose an intermediary-coalition is composed of $\mathrm{Y}$ members. They announce compensation schedules for "depositors"--agents who turn their wealth endowment over to the coalition for investment. The investment policy is that coalition members will evaluate $Y$ projects, funding only those which receive a favorable evaluation, at a level $x$. Agents whose projects are evaluated agree to deposit their unit of the investment good with the intermediary and to deliver to it all output of the consumption good. All depositors, including those whose projects are evaluated, are promised a payment in period two of 


$$
x E\{r \mid e=g\} \pi(e=g) y
$$

units of the consumption good. Coalition members agree to be residual claimants, after depositors, and in period one their expected consumption is defined by the lottery (3.3). This fully specifies the policies-evaluation, investment and compensation schedules--of an intermediarycoalition in this environment.

Actually, there will be competition among these organizations. Given that there are constant returns to scale in information production, and that all agents have equal access to the evaluation technology, there is freedom of entry. Size is not a matter of indifference, however, and intermediaries must be large (that is, evaluate and invest in a large number of projects) to be successful. This is so because compensation promised to depositors can be paid almost surely only if the intermediary is perfectly diversified across projects.

If there are not a large number of evaluators in a coalition, the realized fraction of evaluations that are of type $e=g$ is random. Then, with positive probability there will be an incentive for the coalition of evaluators to misrepresent this fraction. Suppose for a coalition of small finite size no evaluations are of type $e=g$, an event that has positive probability. The coalition will have an incentive to claim otherwise, for only then will its members have a positive probability of positive consumption. Thus, the intermediary-coalitions described here must invest in a large number of projects, and borrow from an even larger number of depositors. With a countable infinity of agents in the economy, however, this is feasible and not inconsistent with competition.

Even though all agents are assumed risk-neutral, intermediarycoalitions "diversify" their assets and liabilities. They mimic the 
other stylized facts about real-world intermediaries, too. That is, they produce information about investment opportunities, and they issue their own differentiated claims. Moreover, an arrangement with competition between these organizations supports the optimal allocation for the environment considered previously--the one with pathological honesty. Consequently, it must be optimal for the present environment which has more constraints. $\underline{3}$ /

4. Equilibrium Allocations With Adverse Selection

In this section the $i$ subscript is reintroduced, resulting in an economy with adverse selection. In order to focus on this feature exclusively, we invoke the extreme assumption that an evaluation provides no additional information about a project's return other than the information contained in $i$. Formally, this means that $i$ is sufficient relative to the pair (i,e) in forecasting $r$, or,

(4.1) $\quad \pi(r \mid i, e)=\pi(r \mid i)$, for all $(i, e, r)$.

It is also assumed that $i$ is never perfectly deducible from knowledge of e and $r$; that is

(4.2) $0<\pi(i \mid e, r)<1$, for all $(i, e, r)$.

Thus, it can never be proven ex post that an agent misrepresented his type. For this economy, absent private information, there would be no reason to evaluate projects as this procedure is costly and produces no additional information to that contained in $i$. 
Pathological Honesty

Unlike the economy studied earlier, when we allow for heterogeneous agents, there is generally not a unique Pareto optimal allocation. It may therefore prove instructive to begin by considering the simplest and most familiar case--one in which all agents are pathologically honest. In this case, an optimal allocation can be supported with markets, and it is easily demonstrated that equilibrium consumption allocations depend on the relative proportions of agents in each class. If, for example,

(4.3) $\quad x \pi(i=g)<1$,

type $g$ agents are the ones in limited supply, and all gains from trade accrue to them. Therefore, some type $\mathrm{b}$ projects are funded in equilibrium and the market rate of interest is $\mathrm{E}\{\mathrm{r} \mid \mathrm{i}=\mathrm{b}\}$. Reversing inequality (4.3) results in the market rate of interest increasing from $E\{r \mid i=b\}$ to $\mathrm{E}\{\mathrm{r} \mid \mathrm{i}=\mathrm{g}\}$, and the gains from trade accruing to type $\mathrm{b}$ agents. This latter case is easily tractable but uninteresting from our point of view, for then markets can be used to support an optimal allocation whether or not agents misrepresent. Throughout this section, therefore, our attention is restricted to environments in which (4.3) holds.

Given (4.3), and assuming all agents are pathologically honest, the equilibrium allocation, in the set of feasible allocations, is the one which maximizes the welfare of type $g$ agents subject to the resource constraints $(2.1)$ and $(2.2)$ and also to an individual rationality constraint requiring that type $b$ agents are at least as well off as under autarky. This result is probably familiar, and for brevity we will not set it out formally. What is important though, and what we next demon- 
strate, is that the same result holds when $i$ is private, and agents are willing to misrepresent.

Agents May Misrepresent, but Legal Restrictions Prohibit Financial Intermediaries

We next characterize an equilibrium for an economy in which agents are differently endowed (have different $i$ values), and in which they will misrepresent private information if that is advantageous. For the time being though, we suppress the formation of intermediarycoalitions, as previously defined, by arbitrarily assuming that they're illegal. More precisely, we assume that agents can contract bilaterally, but cannot form groups of three or more with rules that specify the actions (evaluations or investment), or the compensations of group members. This assumption is a useful fiction that allows us to sharply contrast the world sans intermediaries with the world in which they exist. Note that with this assumption, no agent will produce information by evaluating. The reason is precisely the same as in the previous section; there is no way to realize a return on an investment in information. Without coalitions, the market for information fails and there is no way to sell it.

Our candidate for the equilibrium allocation is the solution to the program

$$
\begin{aligned}
& \text { (4.4) } \quad \max \mathrm{E}\left\{\mathrm{c}_{i \mathrm{r}} \mid i=g\right\} \\
& \left(x_{i}\right),\left(c_{i r}\right) \geqslant 0
\end{aligned}
$$


subject to

$$
\begin{array}{ll}
\text { (4.5) } & \sum_{i} \pi(i) E\left\{c_{i r} \mid i\right\} \leqslant \sum_{i} \pi(i) x_{i} E\{r \mid i\} \\
\text { (4.6) } & \sum_{i} x_{i} \pi(i) \leqslant 1 \\
(4.7) \quad & x_{i} \leqslant x \\
\text { (4.8) } & E\left\{c_{i r} \mid i\right\} \geqslant E\left\{c_{j r} \mid i\right\} \text {, for all } i, j \varepsilon\{g, b\} \\
\text { (4.9) } & E\left\{c_{i r} \mid i\right\} \geqslant E\{r \mid i\}, \text { for all } i .
\end{array}
$$

Here $x_{i}$ is investment in a project of type $i$, and $c_{i r}$ is consumption of a type $(i, r)$ agent. Constraint $(4.5)$ is that per capita consumption is bounded by per capita production. Constraint (4.6) is that per capita investment is constrained by the availability of the investment good. Constraint (4.7) is that investment in a project is bounded by $x$. Constraints (4.8) are incentive constraints; namely, that it is never in the interest of agents to misrepresent their type. Finally, (4.9) is that both agent types must be at least as well off as under autarky.

The solution to this program is almost immediate. First $\mathrm{c}_{\mathrm{gb}}$, that is consumption of good type agent with a bad project realization, $(i=g, r=b)$, may be taken to be zero. If it were not, $c_{g g}$ could be increased and $c_{g b}$ reduced, holding expected consumption $E\left\{c_{i r} \mid i=g\right\}$ fixed. This would have no affect upon the objective function or the technology constraints $(4.5)-(4.7)$, and (4.9). It would introduce slack in the key incentive compatibility constraint

$$
E\left\{c_{b r} \mid i=b\right\} \geqslant E\left\{c_{g r} \mid i=b\right\}
$$


Thus, we are assuming that the parameters are such that this constraint is binding (e.g., that it is not in the interest of type $i=b$ to claim to be of type $i=g$ ). To find the necessary and sufficient conditions to insure that it is binding, we solve the program without that constraint, and then restrict the parameters to be such that the constraint is violated, for that allocation.

If we solve the program without constraints (4.8), a solution is

$$
\begin{aligned}
& c_{g g}^{\circ}=\frac{x F\{r|i=g|-E\{r \mid i=b\} \quad(x-1)}{\pi(r=g \mid i=g)} \\
& c_{g b}^{\circ}=0 \\
& x_{g}^{\circ}=x \\
& c_{b b}^{\circ}=c_{b g}^{\circ}=E\{r \mid i=b\}
\end{aligned}
$$

(4.10) $\quad x_{b}^{\circ}=[1-x \pi(i=g)] / \pi(i=b)$.

Therefore, we must restrict the parameters such that

(4.11) $\quad E\left\{c_{i r} \mid i=b\right\}=c_{g g}^{0} \pi(r=g \mid i=b)>E\{r \mid i=b\}$,

which is the necessary and sufficient condition for the key incentive constraint ( 4.8$)$ to be binding. By selecting $x$ sufficiently large, this is always possible, as $E\{r \mid i=g\}>E\{r \mid i=b\}$.

With the incentive constraint binding, the optimal allocation is characterized by $c_{b}^{*}$ the market interest rate, $c_{g g}^{*}$ the compensation of an entrepreneur if the project has $r=g$, and $x_{b}^{*}$ the amount invested in each of the type $\mathrm{b}$ projects. Now 
(4.12) $\quad c_{b}^{*}=\max \left\{E\{r \mid i=b\}, c_{g g}^{*} \pi(r=g \mid i=b)\right\}$

(4.13) $\quad \chi \pi_{i}(i=g)+x_{b}^{*} \tau_{i}(i=b)=1$

(4.14) $\quad c_{g g}^{*} r(i=g, r=g)+c_{b}^{*} r(i=b)=k E\{r \mid i=g\} \pi(i=g)+$

$$
x_{b}^{*} E\{r \mid i=b\} \quad \pi(i=b) \text {, }
$$

are the three binding constraints, which can be solved for the equilibrium $c_{b}^{*}, c_{g g}^{*}$ and $x_{b}^{*}$. Note, further, that $x_{g}^{*}=x, c_{g b}^{*}=0, c_{b b}=c_{b}^{*}$ and $c_{b g}=c_{b}^{*}$. This fully defines our candidate for the equilibrium allocation.

Support

One way in which this allocation could be supported is for all individuals with promising projects to become entrepreneurs, as well as fraction $x_{b}^{*} / x$ of those agents with poor projects. Entrepreneurs agree to invest their endowment of the investment good in their project and to fund the remainder of the investment, namely $x-1$, by issuing shares to investors. An entrepreneur receives compensation $c_{g g}^{*}$ if $r=g$, and zero otherwise.

From (4.12), those endowed with poor projects are indifferent between becoming entrepreneurs or investors, as their expected return in either activity is $c_{b}^{*}$. In equilibrium, fraction $x_{b}^{*} / x$ of type $b$ agents become entrepreneurs and the rest become investors. Thus, this equilibrium entails some mimicking by agents endowed with type b projects, who intentionally misrepresent that they have type g. Agents actually endowed with good projects attempt to differentiate themselves as much as possible by offering to consume zero when $r=b$. But they cannot do so perfectly due to the bound on consumption, $c \geqslant 0$. Therefore, the equi- 
librium is one which is partially separating by agent type, the degree of separation determined endogenously. This is unlike most signaling models in which agents are either perfectly separated by type, or not separated at all (See Spence [1974]). Section 6 presents a numerical example which should help to clarify this result.

\section{Adverse Selection; Intermediary-Coalitions Permitted}

In this section $j$ denotes what type an agent reports himself to be, while $i$ continues to denote the agent's true type. Attention is restricted to those arrangements in which it is never in the interest of anyone to misrepresent his type, the so-called "simple direct mechanisms." Justification for this restriction is the revelation principle. This principle insures (for a class of economies including ours) that if a particular arrangement entails lying in equilibrium, then there exists another arrangement which does not, and which has the same equilibrium allocation. 4 /

As before, we conjecture that a particular Pareto optimum allocation is an equilibrium allocation. It is the feasible allocation which maximizes the utility of type $g$ agents subject to the constraint that it is in the interest of type $b$ to participate. The order of presentation is as follows. First, we define the candidate allocation as the solution to a math program. Second, we define an equilibrium allocation. Third, we prove that the candidate allocation is an equilibrium allocation. Fourth, we prove the equilibrium is unique. Fifth, and finally, we support the equilibrium allocation with an arrangement of competing 
intermediary-coalitions. Throughout this section maintained assumptions are $(4.1),(4.2)$ and $(4 \cdot 3)$.

Before presenting the program whose solution defines the candidate allocation, it is necessary to introduce notation to specify the direct mechanisms. This notation is:

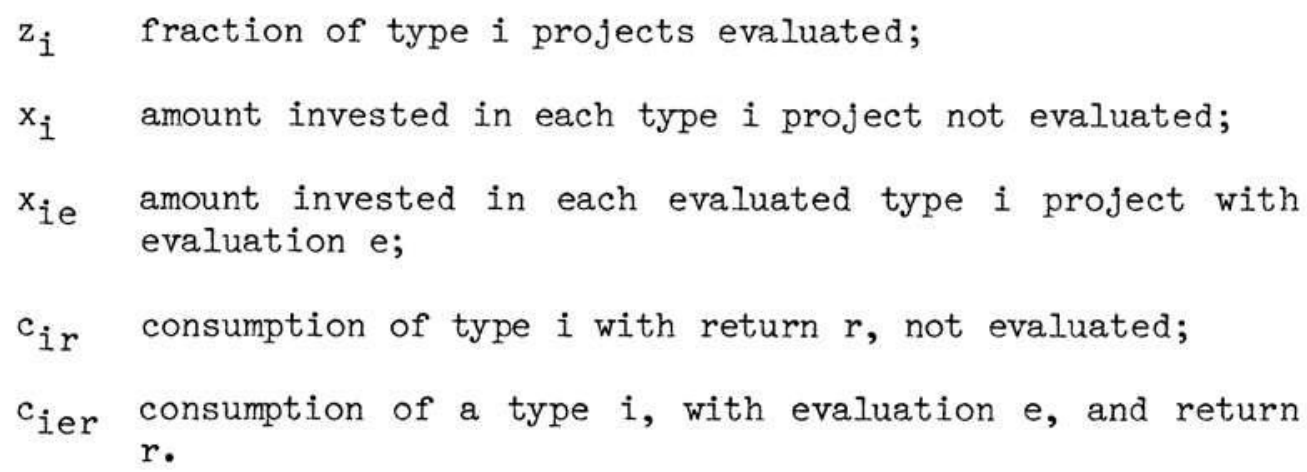

In addition, $z$ denotes the pair of $z_{i}, x$ the set of two $x_{i}$ and four $x_{i e}$, and $c$ the set of four $c_{i r}$ and eight $c_{i e r}$. Finally, $u_{i}(c, z, j)$ is the expected consumption of a type $i$ who reports to be a type $j$; thus

$$
u_{i}(c, z, j)=z_{j} E_{e, r}\left\{c_{j e r} \mid i\right\}+\left(1-z_{j}\right) E_{r}\left\{c_{j r} \mid i\right\}
$$

The subscripts on the $\mathrm{E}$ operator are the random variables over which the expectation, or averaging, operator is taken.

With this notation our candidate for an equilibrium allocation is the solution to the program

$$
\text { (5.1) } \max _{x, c, z \geqslant 0} u_{i=g}(c, z, j=g)
$$

subject to

Investment good resource constraint:

(5.2) $\quad E_{i, e}\left\{z_{i}\left(x_{i e}+1\right)+\left(1-z_{i}\right) x_{i}\right\} \leqslant 1$. 
Consumption good constraint:

$$
E_{i}\left\{u_{i}(c, z, j=i)\right\} \leqslant E_{i}\left\{z_{i} E_{e, r}\left\{r x_{i e} \mid i\right\}+\left(1-z_{i}\right) E_{r}\left\{r x_{i} \mid i\right\}\right\} .
$$

Incentive constraints:

(5.4) $\quad u_{i}(c, z, j=i) \geqslant u_{i}(c, z, j \neq i)$ all $i$

(5.5) $\quad u_{i}(c, z, j=i)>E_{r}\{r \mid i\} \quad$ a.l i.

Other constraints:

(5.6) $\quad z_{i} \leqslant 1$ all $i$

(5.7) $\quad x_{i} \leqslant x \quad$ all $i$

(5.8) $\quad x_{i e} \leqslant x \quad$ all i,e.

This is not a linear program, but by changing variables it can be transformed into one. This can be accomplished as follows: substitute $u_{i 1}$ for $z_{i}, u_{i 2}$ for $\left(1-z_{i}\right), v_{i e}$ for $z_{i} x_{i e}, v_{i}$ for $\left(1-z_{i}\right) x_{i}, w_{i e r}$ for $z_{i} c_{i e r}$ and $w_{i r}$ for $\left(1-z_{i}\right) c_{i r}$. Add the linear constraints $u_{i 1}+u_{i 2}=$ 1. Note $(5.7)$ becomes $v_{i} \leqslant x u_{i 2}$ and $(5.8) v_{i e} \leqslant x u_{i 1}$. It is now a linear program in $\mathrm{u}, \mathrm{v}$ and $\mathrm{w}$.

We assume that $\chi$ is sufficiently large and e contains sufficient information about $r$ that the solution value of this program exceeds that of the previous one, (as for the example in the next section); then, this program is interesting and not so formidable. First, all good projects are evaluated and funded independent of their evaluation outcome. Further, $c_{\text {ger }}=0$ unless both $e=g$ and $r=g$. If this were not the case, slack could be introduced into the binding incentive constraint, which is the one which insures that it is not in the interest of type b 
to claim to be of type $\mathrm{g}$. This slack could be produced without affecting the objective function or any other constraints. Evaluating projects with $i=b$ is wasteful of resources and does not help with respect to the key incentive constraints. Consequently, no projects of type b are evaluated at an optimum.

Using these facts, $z_{g}^{*}=1$ and $z_{b}^{*}=0$ while $x_{g g}^{*}=x_{g b}^{*}=x \cdot$ At the optimum, all other variables are zero except for $x_{b}^{*}, c_{g g g}^{*}$, $c_{b g}^{*}$ and $\mathrm{c}_{\mathrm{bb}}^{*}$. The solution to the problem is not unique. Given any solution, changes in $\mathrm{c}_{\mathrm{bg}}^{*}$ and $\mathrm{c}_{\mathrm{bb}}^{*}$ which do not alter type $\mathrm{b}$ expected consumption yield alternative optimal allocations. Consequently, only $\mathrm{c}_{\mathrm{b}}^{*} \equiv$ $E_{r}\left\{c_{i r}^{*} \mid i=b\right\}$ is uniquely determined. It, along with $c_{g g g}^{*}$ and $x_{b}^{*}$, remains to be determined.

These three elements can be deduced from knowledge of the binding constraints. First, constraint $(5.2)$ is binding, so

$$
x \pi(i=g)+x_{b}^{*} \pi(i=b)+\pi(i=g)=1 .
$$

Second, incentive constraint (5.4) with $i=b$ and $j=g$, or constraint (5.5) with $i=b$, is binding

$$
c_{b}^{*}=\max \left\{E\{r \mid i=b\}, c_{g g g}^{*} \pi(e=g, r=g \mid i=b)\right\}
$$

as is resource constraint $(5.3)$, or,

$$
\begin{aligned}
c_{g g g}^{*} \pi(i=g, e=g, r=g) & +c_{b}^{*} \pi(i=b)= \\
& x_{b}^{*} E\{r \mid i=b\} \pi(i=b)+x E\{r \mid i=g\} \pi(i=g) .
\end{aligned}
$$

Equations (5.9)-(5.11) have a unique solution which is nonnegative. Note that this allocation does not maximize per capita consumption. Some resources, namely $\pi(i=g)$ of the investment good, are allo- 
cated to evaluation which provides no additional information about a project's return to that contained in $i$. It is however, an efficient allocation given the resource and incentive feasibility constraints. Remember, also, that for this allocation to be the optimum, the resulting value of the objective function (5.1) must exceed the value of that for program (4.4)-(4.9). The numerical example in the next section established that the set of parameters for which this holds is nonempty Essentially if $e$ is a sufficiently good indicator of $r$, and $x$ is sufficiently large, this will be the case.

Definition: An allocation $\left(c^{0}, x^{0}, z^{0}\right)$ is an equilibrium if no subset of agents, with fraction $\pi^{\mathrm{d}}(\cdot)$ of agent types, can achieve a different allocation $\left(c^{d}, x^{d}, z^{d}\right)$ which satisfies $\left.\left.i\right), i i\right)$ and iii) below.

We shall refer to this subset of agents, indicated with the dsuperscript, as a "deviant" or "breaking" coalition.

i. $u_{i}^{d}>u_{i}^{0}$ for some type i. (Here, $u_{i}^{a}$ denotes the utility of a type $i$ agent resulting from allocation a).

ii. Constraints $(5.2)-(5.8)$ are satisfied with the $\pi^{\mathrm{d}}(\cdot)$ proportions of agent types.

iii.a) If $u_{i}^{d}<u_{i}^{0}$ then $\pi^{d}(i)=0$,

b) if $u_{i}^{d}=u_{i}^{0}$ then $\pi^{d}(i) \leqslant \pi(i)$,

c) if $u_{i}^{d}>u_{i}^{0}$ then $\pi^{d}(i) \geqslant \pi(i)$.

Discussion: Condition iiia) requires that, to attract members, a deviant coalition must make them at least as well off. Condition iiib) deals with ties. It states that when agents of type $i$ are indifferent between an 0-allocation and a d-allocation, some of them may go to the deviant coalition. However, as indicated by iilc), the deviant coalition cannot 
attract higher than population proportions of type $i$ agents unless it makes them strictly better off.

Proposition 1: The allocation defined by solution to the program (5.1)(5.8) is an equilibrium allocation. [Following our notational convention, this is called a *allocation and $\left.u_{i}^{*} \equiv u_{i}\left(c^{*}, z^{*}, j=i\right)\right]$.

$\underline{\text { Proof }}$

By construction, both types of agents weakly prefer the *-allocation to autarky. Thus, to attract anyone, a d-coalition must attract some agents of both types. This, in turn, requires that some agents be made better off (by condition i), and no agents made worse off (by iiia). Since the *allocation is itself a Pareto optimum, the dcoalition, therefore, must attract better-than-population-proportions in the sense that $\pi^{\mathrm{d}}(\mathrm{g})>\pi(\mathrm{g})$. From iiib) and iiic) to attract betterthan-population-proportions requires that: $u_{g}^{d}>u_{g}^{*}$ and $u_{b}^{d}=u_{b}^{*}=c_{b}^{*}$. However, these expected consumptions are not incentive feasible. If the expected consumption of a type $g$ agent is higher in the d-coalition than it is in the *-coalition, then by $(5.10) u_{i=b}\left(c^{d}, z^{d}, j=g\right)>c_{b}^{*}$. Every type $b$ agent would want to join the d-coalition and misrepresent type. Thus, a d-coalition cannot simultaneously satisfy i)-iii), and the proposition is proved.

Proposition 2: The *allocations are the only equilibrium allocations.

$\underline{\text { Proof }}$

Any allocation that is not a Pareto optimum could be broken by a deviant coalition of the whole. Thus, without loss of generality, we restrict our attention to Pareto optimal allocations. Now consider any 
Pareto optimal allocation other than a *allocation. We call this a "pallocation." If some Pareto optimal allocation results in utilities $u_{b}^{p}$ and $u_{g}^{p}$, then there exists an allocation which also results in the se utilities with $c_{b r}^{p}=u_{b}^{p}$ for all $r, c_{g b}^{p}=0$, and $c_{\text {ger }}^{p}=0$ unless $e=g$ and $r=$ g. Further, $c_{g g}^{p}$ and $c_{g g g}^{p}$ may be set so that the expected utility of type $i=g$ agents is the same, whether or not they are evaluated. Note that $\mathrm{z}_{\mathrm{b}}^{\mathrm{p}}=0$ as Pareto optimality requires that no type $i=b$ projects are evaluated and, of course, that $x_{g}^{p}=x_{g e}^{p}=x$.

To break any p-allocation, we construct a deviant coalition with the following properties. Increase the fraction of type $i=g$ agents until it is just high enough that investment in type $i=b$ projects is driven to zero. This will occur when

$$
\pi^{d}(i=g)=\frac{1-\pi(i=g) z_{g}^{p}}{1+x-\pi(i=g)\left(z_{g}^{p}+\chi\right)}
$$

All incremental $i=g$ projects--those in excess of population proportions--are evaluated, and funded at level $x$. Owners of these projects are assigned the same consumptions as other type $i=g$ agents whose projects are evaluated. By adding and evaluating type $i=g$ projects, investment funds can be reallocated from low expected return projects to high expected return projects. Production of the consurption good increases by an amount that exceeds the consumption of the incremental type $i=g$ agents. Consequently, there will be slack, say $\delta>0$, in the consumption good constraint (e.g., constraint 5.3 with $\pi^{\mathrm{d}}(\cdot)$ fractions of agent types).

$$
\text { Now, let } c^{\theta}=\theta c^{p}+(1-\theta) c^{*} \text { for } 0<\theta<1 \text {. Next, increase }
$$

every component of $c^{\theta}$ by $\varepsilon>0$ where 


$$
\varepsilon=\theta\left(u_{b}^{p}-u_{b}^{*}\right)
$$

Choose a $\theta$ such that $\varepsilon<\delta$. The resulting consumption contract (which is a 12-tuple) is denoted $c^{d}$. Other elements of contract $d$ are $x_{g}^{d}=x_{g e}^{d}=$ $x, x_{b}^{d}=0, z_{b}^{d}=0$, and

$$
z_{g}^{d}=\frac{1+\pi(i=g)\left(x z_{g}^{p}-z_{g}^{p}-x\right)}{1-\pi(i=g) z_{g}^{p}}
$$

where $\mathrm{z}_{\mathrm{g}}^{\mathrm{d}}$ is the value of $\mathrm{z}_{\mathrm{g}}$ which solves the investment resource constraint, given that $\pi^{\mathrm{d}}(\mathrm{i}=\mathrm{g})$ satisfies $(5.12)$ and all other variables in the d contract are set as specified.

The $c^{\theta}$ contract satisfies incentive constraints (5.4) and (5.5) because the constraints are linear in $c$, and $c^{\theta}$ is a convex combination of $c^{p}$ and $c^{*}$ which both satisfy these constraints. Adding $\varepsilon$ to all elements of $c$ increases both sides of (5.4) by $\varepsilon$ and cannot violate the inequality. It adds $\varepsilon$ to the left-hand side of (5.5) and cannot violate that inequality either. Contract $d$ is resource and incentive feasible with $\pi^{d}(\cdot)$ fractions of agent types. As $u_{b}^{d}=u_{b}^{p}, u_{g}^{d}>u_{g}^{p}, \pi^{d}(i=g)>$ $\pi(i=g)$ and $\pi^{d}(i=b)<\pi(i=b)$, requirements (i) and (iii) for a blocking group are satisfied as well. Thus, the p-allocation is broken by the dallocation and Proposition 2 is proved.

Supporting the Allocation with Competing Intermediary-Coalitions

For this economy an intermediary-coalition is defined as a coalition of $\mathrm{n}$ agents of type $\mathrm{b}$, where $\mathrm{n}$ is large (see footnote 2). In period one, the coalition commits itself to the following policy. 
1. Fach coalition member will evaluate one project.

ii. For each unit of the investment good deposited with it, the intermediary agrees to deliver $c_{b}^{*}$ units of the consumption good the next period. These depositors give the intermediary the right to invest in their project and to receive the entire output if the intermediary chooses to invest. Total deposits are limited to $n\left[x \pi(i=g)+x_{b}^{*} \pi(i=b)\right]$.

iii. The intermediary agrees to evaluate $n$ projects, the owners of which must deliver a unit of the investment good prior to the evaluation. The intermediary agrees to fund each of the $\mathrm{n}$ projects evaluated. (Recall that this activity is publicly observable). Project owners (entrepreneurs) are promised $c_{\text {ggg }}^{*}$ units of the consumption good next period if the project has evaluation $e=g$ and return $r=g$, and zero otherwise. The intermediary also guarantees that of all projects evaluated, the fraction $\pi(e=g \mid i=g)$ will receive a good evaluation.

iv. Members of the coalition are residual claimants and share equally in profits.

This arrangement is incentive feasible as long as $\mathrm{n}$ is large. Moreover, freedom of entry into the business of intermediation guarantees that the expected consumption of coalition members is $\mathrm{c}_{\mathrm{b}}^{*}$, and thus that the arrangement is resource feasible as well.

Ex-Post versus Ex-Ante Efficiency

In a sense, it is important that intermediary-coalitions can commit in advance to monitor projects of those who claim to be of type g. By construction, only those who actually have promising projects will so claim in equilibrium, and as a result monitoring is unnecessary and wasteful ex post. This ex post inefficiency, however, is a necessary part of the ex ante efficient arrangement. If it were not part of the technology to so commit, our arrangement would not constitute an equilibrium. But, whether or not it is possible to commit in this way is not crucial to the existence of intermediary-coalitions. $\frac{5}{}$ Nor is it crucial 
that $e$ provides no information in addition to that contained in $i$, as was assumed in deriving (5.9)-(5.11). If this assumption were dropped, the equilibrium allocation would still be the solution to program (5.1)-(5.8).6/ In either of these cases, competing intermediary-coalitions can still be used to support the equilibrium allocation.

In summary, in this environment as in the previous one competing intermediary-coalitions support Pareto optimal allocations which maximize the welfare of type $g$ agents. As before, intermediary-coalitions mimic our stylized facts about real-world intermediaries. They produce information about projects, issue differentiated claims and "diversify" assets and liabilities. And each of these features is an essential part of the equilibrium arrangement.

\section{A Numerical Example}

In this section, we briefly present a numerical example [consistent with assumptions (4.1), (4.2) and 4.3)] showing solutions to programs $(4.4)-(4.9)$ and $(5.1)-(5.8)$. For simplicity, we shall refer to the former as the "no intermediary solution" and to the latter as the "intermediary solution." Assume the following parameter values:

$$
\begin{aligned}
& \pi(i=g)=.01 \\
& \pi(e=g \mid i=b)=.60 \\
& \pi(e=g \mid i=g)=.95 \\
& \pi(r=g \mid i=g)=.90 \\
& \pi(r=g \mid i=b)=.05
\end{aligned}
$$




$$
\begin{aligned}
& r_{g}=2 \\
& r_{b}=1 \\
& x=50 .
\end{aligned}
$$

This set of probabilities can be used to derive all the $\pi(i, e, r)$ parameters, given that $\mathrm{e}$ and $\mathrm{r}$ are independently distributed conditional upon i. From the above $E(r \mid i=g)=1.9$ and $E(r \mid i=b)=1.05$.

The no intermediary solution is characterized by the following values:

$$
\begin{aligned}
& x_{g}^{*}=50 \\
& x_{b}^{*}=.50505 \\
& c_{b}^{*}=1.2607 \\
& c_{g g}^{*}=25.214 .
\end{aligned}
$$

Expected consumption of type $g$ agents is 22.692 , and thus, both classes of agents prefer this solution to autarky. [Since $c_{b}^{*}>E(r \mid i=b)$, and $\left.E\left(c_{i r} \mid i=g\right)>E(r \mid i=g)\right]$. Since $x=50$ and $\pi(i=g)=.01$, only one half of total investment can be in type (i=g) projects. The other half will be in projects offered by mimics, who dishonestly claim to have type g projects. The expected return to mimicking is $\pi(r=g \mid i=b) c_{g g}^{*}=1.2607$, and therefore, these agents are indifferent between engaging in this activity and investing, as required for equilibrium.

For the same parameters, the intermediary solution is characterized by the following values:

$$
\begin{aligned}
& x_{g}^{*}=50 \\
& x_{b}^{*}=.49495 \\
& c_{b}^{*}=1.1486
\end{aligned}
$$




$$
\mathrm{c}_{\mathrm{ggg}}^{*}=38.288 .
$$

Expected consumption of type $\mathrm{g}$ agents is 32.736 , so both classes prefer this solution to autarky. However, expected consumption of type $g$ agents is greater here than it is in the previous case, and thus, if financial intermediaries can be formed, they will be. Put another way, the intermediary solution is a Pareto optimum for this economy, unless it is prohibited. Note that in the intermediation case, all agents which represent themselves as type $g$ are actually of that type; in other words, there is no mimicking. A fraction, $\pi(e=b \mid i=g)=.05$, of $(i=g)$ agents get zero consumption even if the project realizes a good return. However, no type $g$ agent knows ex ante if he will be among this five percent group, and this is part of the mechanism which results in an ex ante efficient allocation.

In this particular example, financial intermediaries "look bad," because in their presence average per capita consumption declines, totally at the expense of type $b$ agents. This is not a general result, however. It is due to assumption (4.1) that e contains no information in addition to that contained in $i$.

\section{Possible Extensions}

For the examples considered there are but two possible returns and but two possible evaluation outcomes. This did facilitate the characterization of the equilibrium allocations but played no essential role in the analysis. The program (5.1)-(5.8) whose solution defines the 
equilibrium allocation (provided, of course, there is a sufficient proportion of type $b$ agents) is not changed if the sets of possible $e$ and $r$ are expanded. Extending the results to the case in which the evaluation e provides information in addition to that contained in type $i$ concerning return $r$ is also immediate. The equilibrium allocation that is supported by competing intermediaries is again defined by the solution to program (5.1)-(5.8). Another possible modification is to permit correlation among project returns. This is a relatively easy extension if project returns depend on common events which are publicly observed. It does not disturb any of the major conclusions presented in this paper. (See Diamond, [1982]).

An extension which does not appear to be so straightforward, however, is one in which there are more than two agent types. Although Spence [1978] has successfully dealt with multiple agent types in an insurance economy, this extension is more difficult in the present environment and is the subject of continuing research. 
Footnotes

I/By financial intermediaries, we mean commercial banks, thrift institutions, loan companies, consumer finance companies, etc.--the socalled "asset transformers." (Gurley and Shaw [1956]). We do not include security brokers, dealers and exchanges. These are perhaps better described as an arrangement for executing security transactions by providing payment, delivery and accounting, as well as a system for arriving at a price.

2/This can be accomplished, for example, as follows. Let $n, n$ $\varepsilon\{1,2,3 \ldots\}$ index agents, and consider the sequence $\{1,1,2,1,2,3,1,2,3,4,1 \ldots\}$. Agent $\mathrm{n}$ is assigned to intermediary $\mathrm{k}$, for $\mathrm{k}$ $=1,2,3$. ., if the $\mathrm{n}$-th element of this sequence is $\mathrm{k}$. Note the fraction of agents in any intermediary is zero.

In most of the environments considered here, each intermediary must have a countable infinity of borrowers and lenders. We chose to examine this limiting case because it is simplest. At the cost of some added complexity, however, we could modify our environments slightly and obtain essentially the same results with a large but finite constraint on the size of intermediaries. Readers interested in this problem should see Diamond [1982].

$\underline{3} /$ This structure is related to the one considered by Prescott and Townsend [1984a], but differs in that an intermediary-coalition is needed, rather than an entity that receives or delivers goods based upon agents' statements of type. Here, optimal coalitions or syndicates (see Holmstrom [1982]) rather than just optimal contracts (see Townsend [1979]) arise, as the result of competitive behavior. Our intermediarycoalitions could also be viewed as a nexus of contracts (Coase [1937]) or as an arrangement to economize on transaction costs (Williamson [1975]). 
4/See Harris and Townsend [1981]. If agents were not riskneutral it would be necessary to consider consumption lotteries contingent upon the observables as in Prescott and Townsend [1984a, 1984b]. If it were not part of the technology to precommit to evaluation subsequent to the report of type, the revelation principle would fail and the analysis would be more difficult.

5/ If it were not feasible, then there would be additional constraints in the Pareto optimum program and the resulting solution would differ. The relevant Pareto optimum for this alternative econony would also require financial intermediaries for its support. The only important difference would be that some type $b$ projects would be evaluated. Then, the choice of whether or not to be an entrepreneur would not perfectly reveal an agent's type. In either case, the key equilibrium condition is that the expected return to type $b$ agents be the same, whether they choose to be investors, evaluators or entrepreneurs. And in either case, the entrepreneur's compensation schedule is structured so that the difference in expected consumption of a potential entrepreneur for the two agent types be maximal. The second allocation would also be Pareto optimal given the environment, and could not be Pareto dominated by a social planner who, like the intermediaries, could not precommit future actions.

$6 /$ Depending on the parameter values, projects of type ( $i=g, e=b)$ might or might not be funded. Similarly, some projects of type ( $i=b)$ might be evaluated and funded in equilibrium, if and only if their $e=g$. 


\section{BIRLIOGRAPHY}

Coase, R. H., "Ihe Nature of the Firm," Fconomics NS 1937, 4: pp. 386405, reprinted in $G$. J. Stigler and K. E. Bouldings, etc; Readings in Price Theory. Homewood, Illinois: Richard D. Irwin Inc. 1952.

Diamond, Douglas W., "Financial Intermediation and Delegated Monitoring," Center for Security Prices, University of Chicago Working Paper No. 8?, August 1982.

and Phillip Dybvig, "Bank Runs, Liquidity and Deposit Insurance," Journal of Political Economy 91, June 1983, pp. $401-419$.

Fama, Eugene F., "Banking in the Theory of Finance," Journal of Monetary Economics 6, 1980 , pp. 39-57.

Green, Edward J., "Continuum and Finite Player Noncooperative Models of Competition," California Institute of Technology Working Paper, Econometrica, forthcoming.

Gurley, John G. and Edward S. Shaw, "Financial Intermediaries and the Savings-Investment Process," The Journal of Finance, May 1956, pp. 259-275.

Harris, Milton and Robert M. Townsend, "Resource Allocation Under Asymmetric Information," Econometrica 49, January 1981, po. 33-64.

Holmstrom, Bengt, "Moral Hazard in Teams," The Bell Joumal of Economics 13, Autumn 1982, pp. 324-340.

Leyland, Hayne E. and David H. Pyle, "Informational Asymmetrics, Financial Structure, and Financial Intermediation", The Journal of Finance, May 1977, pp.371-88.

Prescott, Edward C. and Robert M. Townsend, "Pareto Optima and Competitive Equilibria With Moral Hazard and Adverse Selection," Econometrica 52, Januaxy 1984a, pp. 21-46.

"General Competitive Analysis in an Fconomy With Private Information," International Fconomic Review 25, February 1984b, pp. $1-20$.

Rothschild, Michael and Joseph Stiglitz, "Equilibrium in Competitive Insurance Markets: An Essay on the Economics of Imperfection Information," Quarterly Journal of Economics 90, November 1976, pp. 629649.

Smith, Bruce D., "Private Information Deposit Interest Rates, and the 'Stability' of the Banking System," Working Paper No. 228, Minneapolis Federal Reserve Bank, 1983.

Spence, Michael A., Market Signaling: Information Transfer in Hiring and Related Screening Processes, Harvard University Press, Cambridge, Massachusetts, 1974 . 
$-34-$

Spence, Michael A., 1978. "Product Differentiation and Performance in Insurance Markets," Journal of Public Economics 10, pp. 427-447.

Townsend, Robert M., "Intermediation With Costly Bilateral Exchange," Review of Economic Studies 45, 1978, pp. 417-425.

, "Optimal Contracts and Competitive Markets With Costly State Verification," Journal of Economic Theory 21, 1979, pp. 265-293.

"Theories of Intermediate Structures," in Carnegie-Rochester Conference Series on Public Policy 18, Spring 1983, pp. 221-272.

Williamson, Oliver E., Markets and Hierarchies, A Study in the Economics of Internal Organization," New York Free Press: 1975. 